\title{
The Impact of Organizational Commitment on Employee Motivation: A Study in Vietnamese Enterprises
}

\author{
Hoai Nam NGUYEN', Quoc Hoi LE², Quang Bach TRAN³, Thi Hoang Mai TRAN, \\ Thi Hai Yen NGUYEN ${ }^{5}$, Thi Thuy Quynh NGUYEN ${ }^{6}$
}

Received: April 09, 2020 Revised: April 18, 2020 Accepted: May 01, 2020

\begin{abstract}
The study examines direct and indirect impacts of organizational commitment on employee motivation through two mediating factors opportunistic behavior and knowledge sharing - in Vietnamese enterprises. The samples were selected by the non-probability sampling method followed convenient sampling, relatively stratified by localities in Vietnam. The sample size was 636 employees in Vietnamese enterprises. The number of collected online questionnaires was 379 , while the number of valid questionnaires was 329 . In the direct survey, the number of distributed questionnaires was 750, while the number of collected questionnaires was 421 and the number of valid questionnaires was 307 . The total number of valid questionnaires used for analysis was 636 . The study used quantitative methods with structural equation modeling analysis. The results indicate that among the components of organizational commitment, normative commitment has both direct and indirect impacts on employee motivation through two mediating factors: opportunistic behavior and knowledge sharing. Meanwhile, affective commitment has only an indirect impact on employee motivation through these mediating factors. Continuance commitment has both direct and indirect impacts; however, it has only an indirect impact on employee motivation through opportunistic behavior. In addition, the results show opportunistic behavior has a negative impact on the knowledge sharing of employees in enterprises.
\end{abstract}

Keywords : Affective Commitment; Continuance Commitment; Normative Commitment; Opportunistic Behavior; Knowledge Sharing; Work Motivation.

JEL Classification Code: J28, J81, M51.

\section{Introduction}

${ }^{1}$ First Author. Lecturer, Faculty of Economics, Vinh University, Vietnam. Email: namnh@vinhuni.edu.vn

${ }^{2}$ Corresponding Author. Associate Professor, Faculty of Economics, National Economics University, Vietnam [Postal Address: 207 Giai Phong Road, Dong Tam Ward, Hai Ba Trung District, Hanoi, 116000, Vietnam] Email: hoilq@neu.edu.vn

${ }^{3}$ Lecturer, Faculty of Economics, Vinh University, Vietnam.

Email: tbach152008@gmail.com

${ }^{4}$ Lecturer, Faculty of Economics, Vinh University, Vietnam.

Email: hoangmaikkt@gmail.com

${ }^{5}$ Lecturer, Faculty of Economics, Vinh University, Vietnam.

Email: haiyenkkt@gmail.com

${ }^{6}$ Lecturer, Faculty of Economics, Vinh University, Vietnam.

Email: ntquynh83@gmail.com

(c) Copyright: The Author(s)

This is an Open Access article distributed under the terms of the Creative Commons Attribution Non-Commercial License (http://Creativecommons.org/licenses/by-nc/4.0/) which permits unrestricted noncommercial use, distribution, and reproduction in any medium, provided the original work is properly cited.
Many studies have shown the importance of organizational commitment and its impacts on employee motivation and organizational performance. According to Meyer and Allen (1991), organizational commitment is considered in two points of view on attitude and behavior approaches. Mowday, Porter, and Steers (1982); Reicher (1985); Salancik (1977); Scholl (1981); and Staw (1977), in the theoretical overview of organizational commitment, showed the difference between attitudinal commitment and behavioral commitment. If an employee is highly committed to his or her organization, he or she will specify its objectives and values; at the same time, he or she will have a great desire to become its member and be ready to express positive organizational citizenship behaviors. Such an employee will be willing to do more work outside his or her duties and responsibilities and always makes the best efforts in the organization. On the contrary, if an employee has no organizational commitment, he or she will be not only non-contributive, but also inclined to leave the organization. According to Hardiningsih et al. 
(2020), organizational commitment is a crucial component of creating accountability. Mobley et al. (1979) show that organizational commitment is a main variable in the process of leaving the organization.

Motivating employees plays an important role in improving the results and performance of the organization. Motivation is both a goal and a means to help employees effectively complete their work. A strong workforce means that every employee understands and commits to the values and goals of the organization. Motivation not only helps employees to do well, but also supports them struggle to achieve the goal. So far, many studies have mentioned and shown the interaction between organizational commitment and employee motivation; for example, the research by Mathieu and Zajac (1990); Lincoln and Kalleberg (1990); Porter, Steers, Mowday, and Boulian (1974); and Tett and Meyer (1993) state that in the model of job satisfaction and organizational commitment, job satisfaction is the cause affecting the organizational commitment and hard and effective work, which are useful behaviors to the organization. According to the study by Stringer and Didham (2011), workers without good payment for their efforts are affected in their intrinsic motivation.

In fact, many enterprises through many activities have paid much attention to organizational commitment to improve the attachment and living quality of employees. Increasing organizational commitment significantly improves organizational benefits, gives employees a comfortable spirit and positive working attitude, and enhances their attachment and dedication. However, most Vietnamese enterprises are small and medium sized; therefore, many of them still have short-term thinking, as well as ineffective and small-scale work methods. Because of immediate profits, such enterprises have no effective measures to care about life needs, working desires, or attitudes, so employees' efforts and interests are ignored. This reduces employee motivation, thereby reducing labour productivity, growth momentum, and long-term development of the enterprises.

Based on studying the factors of organizational commitment in the context of Vietnamese enterprises, this study aims to test and clarify the direct and indirect interactions between organizational commitment and employee motivation through the mediating factors of opportunistic behavior and knowledge sharing. Therefore, the study contributes to an empirical analysis in the context of businesses in emerging economies like Vietnam. In particular, the study emphasizes the indirect effect of emotional-based commitment employee motivation through opportunity behavior of employees.

\section{Literature Review and Hypotheses}

\subsection{Organizational Commitment and Employee Motivation}

Organizational commitment is defined as a firm belief in the organizational goals and values (Meyer \& Allen, 1991). In the same view, Doan et al. (2020) suggested that organizational commitment is the power of identity between an individual and an organization. Mowday et al. (1979); Porter et al. (1974); and Steers (1979) further emphasized that organizational commitment is the willingness of an employee to contribute significant efforts to the organization. According to Meyer and Allen (1991), organizational commitment is a psychological state (a desire, a need, an obligation) that expresses the employee-organization relationship and affects the aspiration to stay with the organization. The authors looked at differences in concepts and then proposed a concept of commitment including three components: affective commitment, continuance commitment, and normative commitment. Meyer and Allen (1991) also emphasized that affective commitment, continuance commitment, and normative commitment should be considered as three components, not three types of commitments. Each employee can experience all three components in his or her commitment.

Affective commitment refers to the affection and attachment of an employee to the organization, feeling himself or herself as one part of the organization. Employees with a strong affective commitment stay with the organization because they like it. Mowday et al. (1982) suggested that affective commitment is influenced by groups of factors such as personal characteristics, structural characteristics, job characteristics, and work experience.

Continuance commitment refers to awareness of the costs and benefits in association with leaving the organization. Employees with a strong continuance commitment stay with the organization because they need to be so. In a classic psychological study, Becker (1960) suggested that commitment to an action would increase when a person has invested, and such investment might be lost if he or she does not continue to act.

Normative commitment refers to a sense of responsibility for staying with the organization. Employees with a strong normative commitment recognize that staying with the organization is an obligation and an ethical standard, even though they may not like it or get fewer benefits than other options. The studies of ethnical commitment provide more theoretical values than experimental values

According to Steers and Porter (1983), work motivation is the desire and willingness of workers to increase efforts towards achieving organizational goals. Motivation has a great 
influence on employees at their work, specifically, helping them to stick more closely with the work and promoting their abilities, qualities, and strengths in performing the work. Kinman (2001) suggests that intrinsic motivation has both normative and affective factors. The author believes that there is a motivation to master (awareness) and curiosity (affection) in individuals, and the key factors are combined with self-determination. On the contrary, the author proposed that extrinsic motivation is linked to an assessment of a predictable outcome. In addition to the groups of direct impact factors of organizational commitment and employee motivation in this study, the mediating factors including opportunistic behavior and knowledge sharing of employees in the enterprise are also mentioned.

Opportunistic behavior refers to seeking personal gain by frauds (Williamson, 1975), essentially breaking commitments and violating obligations and responsibilities to be fulfilled (Morgan \& Hunt, 1994). Opportunistic behavior is considered a form of negative behavior of employees in the organization under governance of the awareness, attitudes, and capabilities of the employees. The members of the organization are influenced by organizational factors such as culture, leadership, power, structure, and groups that employees take part in.

Kothuri (2002) emphasizes that knowledge in an organization is considered as intellectual capital and exists in two main forms: explicit and tacit. Knowledge is currently less dependent on people. Knowledge can be systematized, measured, disseminated, and stored, including information and communication skills and data transmission to others. Tacit knowledge is significantly dependent on the individual and can be created by processing information combined with knowledge and experience. Tsui et al. (2006) state that knowledge sharing is an activity supporting the employees sharing knowledge and experience in order to complete the projects and plans in a quick and economical manner. In addition, knowledge sharing is related to each individual in co-operating with the organization to share information, ideas, suggestions, and expertise to others. The research by Maponya (2004) also shows that knowledge sharing is based on experiences from the work process inside and outside the organization. If knowledge is available among the members, the organization will minimize duplication of decisions and solve problems faster. Effective knowledge sharing will reuse the knowledge of each individual and raise knowledge to a new level.

\subsection{Research Hypotheses}

\subsubsection{Organizational Commitment and Opportunistic Behavior of Employees}

Research on the relationship between commitment and work behavior has produced mixed results. Commitment is found to be related to work behavior in studies by Pierce and Dunham (1987), Steers (1977), etc.; however, it isn't confirmed in other studies (Jarnal, 1984).

In the theoretical framework of relationship marketing, Morgan and Hunt (1994) show there is a negative relationship between opportunistic behavior and trust, which is a prerequisite for a commitment to a long-term relationship between partners. Regarding the individual scope in enterprises, the research by Ritzer and Trice (1969) proved a positive relationship between organizational commitment and employee compensation. Improving the organizational commitment also means the process of creating a stable mentality and long-term attachment, and limiting negative factors and personal opportunistic behaviors in the organization. In order to clarify the impact of organizational commitment on employee opportunistic behavior in the context of Vietnamese enterprises, hypotheses are formulated as follows:

H1: Affective commitment has a negative impact on the opportunistic behavior of employees in Vietnamese enterprises.

H2: Continuance commitment has a negative impact on the opportunistic behavior of employees in Vietnamese enterprises.

H3: Normative commitment has a negative impact on the opportunistic behavior of employees in Vietnamese enterprises.

\subsubsection{Organizational Commitment and Knowledge Sharing of Employees}

According to Morgan and Hunt (1994), cooperative behavior and knowledge sharing are a positive result of commitment. Organizational commitment is considered to have an impact on the level of employees' knowledge sharing with colleagues. Employees who are highly committed to the organization, whether through affective commitment, continuance commitment, or normative commitment, desire to make a certain contribution to the success of the organization. They are willing to share practical knowledge and experiences with colleagues, creating good support in the overall work process and bringing a positive impact on the work completion of the employees. In the context of Vietnamese enterprises, in order to test this relationship more accurately, we design hypotheses as follows:

H4: Affective commitment has a positive impact on the knowledge sharing of employees in Vietnamese enterprises.

H5: Continuance commitment has a positive impact on the knowledge sharing of employees in Vietnamese enterprises. 
H6: Normative commitment has a positive impact on the knowledge sharing of employees in Vietnamese enterprises.

\subsubsection{Organizational Commitment and Employee Motivation}

Organizational commitment has a positive impact on work motivation, performance, and job satisfaction (Mathieu \& Zajac, 1990). Organizational commitment regulates and builds relationships in the organization. At the same time, it creates more supports in the work process of employees through intermediary relationships between management levels and employees. On this basis, it promotes work motivation and performance. Therefore, in order to test the interaction between organizational commitment and employee motivation in the context of Vietnamese enterprises, we set out hypotheses as follows:

H7: Affective commitment has a positive impact on employee motivation in Vietnamese enterprises.

H8: Continuance commitment has a positive impact on employee motivation in Vietnamese enterprises.

H9: Normative commitment has a positive impact on employee motivation in Vietnamese enterprises.

\subsubsection{Opportunistic Behavior and Work Motivation of Employees}

According to Jadhav et al. (2017), employees contribute to the innovation process, therefore it is important for organizations to understand employee expectations to demonstrate innovative work behavior in order to create and maintain an innovative work culture. The economic development and the diversity of enterprise types create significant competitive pressure for organizations desiring to survive and develop in a volatile market. In order to maintain operation and achieve success, many organizations and individuals do not exclude opportunistic behaviors of individuals and groups to create their own benefits, which has a significant impact on the work motivation of other employees and the overall performance of the organization. In the context of Vietnamese enterprises, in order to test the relationship between opportunistic behavior and employee motivation, a hypothesis is formulated as follows:

H10: Opportunistic behavior has a negative impact on employee motivation in Vietnamese enterprises.

\subsubsection{Knowledge Sharing and Work Motivation of Employees}

According to Burgess (2005), motivation encourages employees to share knowledge outside the working group. If the enterprise creates a working environment in which there is open knowledge sharing among employees, employees have a positive effect in creating attachment and motivation for the work process. In addition, the high level of knowledge sharing in enterprises promotes the improvement of professional knowledge and work experience for individuals, helping them work more effectively and creating trust, excitement, and motivation for employees. In order to clarify the relationship between knowledge sharing and employee motivation in Vietnamese enterprises, we set out a hypothesis as follows:

H11: Knowledge sharing has a positive impact on employee motivation in Vietnamese enterprises.

\subsubsection{Opportunistic Behavior and Knowledge Sharing of Employees}

According to Katsikeas, Dionysis, and Daniel (2009), there is a negative impact of opportunistic behavior on trust, thereby affecting the knowledge sharing and performance of enterprises. As a negative aspect in the system of work behaviors, opportunistic behavior is related to the selfseeking behavior of individuals at work. Therefore, when employees have a high level of opportunistic behavior, they tend to restrict the exchange of valuable information with colleagues and partners. This has a significant effect on the relationships between individuals and colleagues in the organization. In the context of Vietnamese enterprises, in order to test the interaction between opportunistic behavior and knowledge sharing of employees, a hypothesis is established as follows:

H12: Opportunistic behavior has a negative impact on the knowledge sharing of employees in Vietnamese enterprises.

\section{Research Method}

\subsection{Research Scale}

On the basis of the theoretical overview and related research works, this article proposes a research model with independent variables of organizational commitment, including affective commitment, continuance commitment, and normative commitment. Intermediate variables are opportunistic behavior and knowledge sharing. The target variable is employee motivation. A Likert scale with five levels (strongly agree; agree; normal; disagree; strongly disagree) was used in this study. The indicators measuring the variables were adjusted in accordance with the characteristics of the sample from previous studies.

In order to determine the variables of organizational commitment, the scale of Meyer and Allen (1991) was 
applied, including 18 observations for three groups of factors: affective commitment (AC): six observations; continuance commitment (CC): six observations; normative commitment (NC): six observations. In order to determine the opportunistic behavior (OPB), the scale of Katsikeas et al. (2009) with five observations was applied. In order to determine the knowledge sharing (KS), the scale of Chennamaneni (2006) with six observations was applied. The scale of Steers and Porter (1983) with six observations was applied for determination of employee motivation (WM).

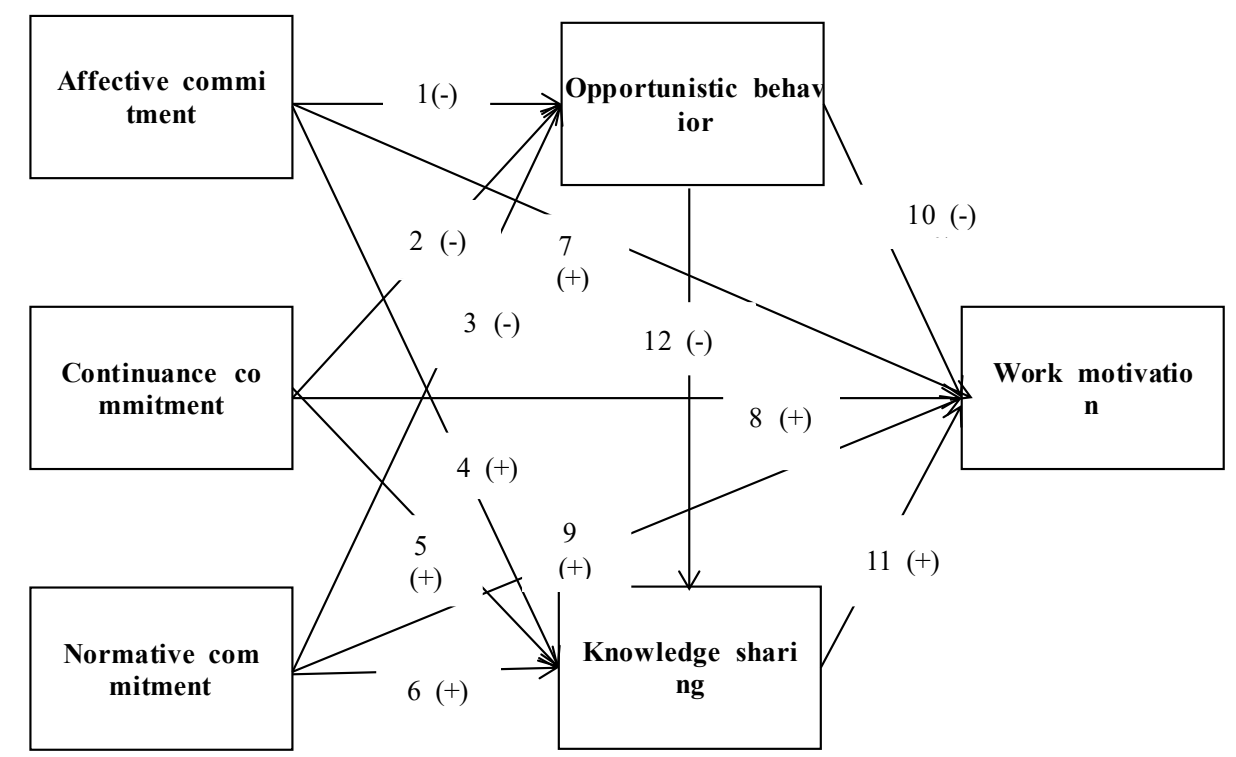

Figure 1: Proposed model of impacts of organizational commitment on employee motivation

\subsection{Research Sample}

The samples selected by the non-probability sampling method followed convenient sampling, relatively stratified by localities in Vietnam. The unit of analysis in this research was employees in Vietnamese enterprises. The sample size for collection was 636 employees. The data collection process was carried out in two ways: direct and online questionnaires. The number of collected online questionnaires was 379, while the number of valid questionnaires was 329. In the direct survey, the number of distributed questionnaires was 750, while the number of collected questionnaires was 421 and the number of valid questionnaires was 307. The total number of valid questionnaires used for analysis was 636. Based on the study by Hair, Anderson, Tatham, and Black (1998) for reference to the expected sample size, the minimum sample size was five times the total number of observed variables. In this research, the number of observations was 35; therefore, the research scale of 636 samples ensures analysis requirements. Data collection was carried out from December 2019 to February 2020.

\subsection{Data Processing}

Quantitative methods are used in this research. The data after collection and cleaning were processed through
SPSS and Amos. Firstly, this research assessed the reliability of the scale with Cronbach's alpha value $>0.7$. Next, it analyzed the exploratory factor analysis (EFA) discovery factor aimed at determining "convergent values" and "discriminant values of the scale". Then, the AMOS was used to assess the suitability of the research model through confirmatory factor analysis (CFA) test. Finally, the research hypotheses were tested by structural equation modeling (SEM) analysis.

\section{Results and Discussion}

\subsection{Testing the Reliability of the Scale}

Cronbach's alpha test analysis results show that the scale's reliability is used in the analysis when Cronbach's alpha coefficients for all variables are $>0.7$. However, the indicator NC6 has a Cronbach's alpha if item delete coefficient of 0.903 , which is higher than the Cronbach's alpha coefficient of the NC variable (0.901). The indicator WM6 has a Cronbach's alpha if item delete coefficient of 0.959, which is higher than the Cronbach's alpha coefficient of the WM variable (0.941). Therefore, in order to increase the suitability of the scale, this article studies two indicators: NC6 and WM6 (see Table 1). 


\subsection{EFA}

After testing the suitability of the scale, we conducted EFA discovery factor for independent, intermediate, and dependent variables. The results show that the data are eligible for analysis because the factor loading is $>0.5$ and satisfies the two conditions as "convergent values" (observed variables converge on the same factor) and "discriminant values" (observed variables belong to one factor and are distinguished from others) (see Table 2).

\subsection{CFA}

The findings show the suitability of the measurement model. Chi square $=1360.591, \mathrm{df}=480$, Chi square/ $\mathrm{df}=2.835(<3), \mathrm{P}=0.000, \mathrm{GFI}=0.879(>0.8), \mathrm{TLI}=$ $0.934(>0.9), \mathrm{CFI}=0.940(>0.9)$, and $\mathrm{RMSEA}=0.054$ $(<0.08)$.

\subsection{SEM analysis}

Through the SEM analysis for the research model, we found that general indicators are satisfactory. In particular, Chi square $=1360.591, \mathrm{df}=480$, Chi square $/ \mathrm{df}=2.835(<3)$, $\mathrm{P}=0.000, \mathrm{GFI}=0.879(>0.8), \mathrm{TLI}=0.934(>0.9), \mathrm{CFI}=$ $0.940(>0.9)$, an RMSEA $=0.054(<0.08)$ (see Figure 2$)$.

The results of estimating the relationships in the model show that the research model is suitable. Except for hypotheses $\mathrm{H} 5$ and $\mathrm{H} 7$, all remaining hypotheses with a significance level of $\mathrm{P}<0.05$ are accepted.

Particularly, for hypotheses H1, H2, and H3 for testing the impacts of organizational commitment factors on employees' opportunistic behaviors in Vietnamese enterprises, the results show that all hypotheses are accepted with a significance level of $\mathrm{p}<0.05$ and weight $<0$. The three factors of affective commitment, continuance commitment, and normative commitment have negative impacts on employees' opportunistic behavior. These results correspond to related studies, such as those by Pierce and Dunham (1987), Steers (1977), Morgan and Hunt (1994), and Ritzer and Trice (1969).
For hypotheses H4, H5, and H6 for testing the impacts of organizational commitment on knowledge sharing in Vietnamese enterprises, the results show that, except for hypothesis H5 with a significance level of P 0.058 $(>0.05)$ under rejection, which meant that continuance commitment has no impact on employees' knowledge sharing, both remaining hypotheses H4 and H6 with significant levels of $\mathrm{p}<0.05$ and positive regression weight are accepted (i.e., affective commitment and normative commitment have positive impacts on employees' knowledge sharing in enterprises). The order of impacts determined by regression weight are affective commitment (0.248) and normative commitment (0.127). These results are similar to the studies by Morgan and Hunt (1994), Tsui et al. (2006), etc.

For hypotheses H7, H8, H9, H10, and H11 for testing the direct impact of factors on employee motivation in Vietnamese enterprises, the results show that except for hypothesis $\mathrm{H} 7$ with a significance level of P 0.749 $(>0.05)$ under rejection, which meant that affective commitment has no direct impact on employee motivation, all the remaining hypotheses with a significance level of $\mathrm{P}<0.05$ are accepted. In particular, with a regression weight of -0.357 , it can be concluded that opportunistic behavior has a negative impact on employee motivation. Meanwhile, with regression weights $>0$, all the factors of affective commitment, continuance commitment, and normative commitment have a positive impact on work motivation. The order of impact is defined as follows: knowledge sharing with regression weight of 0.299 , normative commitment with regression weight of 0.194 , and continuance commitment with regression weight of 0.163 . These results correspond to studies by Mathieu and Zajac (1990), Burgess (2005), etc.

As such, by rejecting the hypotheses H5 and H7 while accepting all the remaining hypotheses, it can be concluded in terms of the relationship between organizational commitment and employee motivation in Vietnamese enterprises as follows:

Table 1: Assessment of the scale's reliability through Cronbach's alpha coefficient

\begin{tabular}{|c|l|c|c|}
\hline No. & \multicolumn{1}{|c|}{ Variables } & Code & Cronbach's alpha coefficient \\
\hline 1 & Affective commitment & AC & 0.882 \\
\hline 2 & Continuance commitment & CC & 0.825 \\
\hline 3 & Normative commitment & NC & 0.903 \\
\hline 4 & Opportunistic behavior & OPB & 0.862 \\
\hline 5 & Knowledge sharing & KS & 0.922 \\
\hline 6 & Work motivation & WM & 0.959 \\
\hline
\end{tabular}


Table 2: Results of EFA

\begin{tabular}{|l|c|c|c|c|c|}
\hline \multicolumn{1}{|c|}{ EFA } & $\begin{array}{c}\text { KMO } \\
\text { coefficient }\end{array}$ & P-value & $\begin{array}{c}\text { Variance } \\
\text { extracted }\end{array}$ & Factor loading & Conclusion \\
\hline $\begin{array}{l}\text { Independent variables } \\
\text { and intermediate } \\
\text { variables }\end{array}$ & 0.923 & 0.000 & 65.684 & All loadings $>0.5$ & $\begin{array}{c}\text { Ensuring analysis } \\
\text { requirements }\end{array}$ \\
\hline Dependent variables & 0.891 & 0.000 & 86.268 & All loadings $>0.5$ & $\begin{array}{c}\text { Ensuring analysis } \\
\text { requirements }\end{array}$ \\
\hline
\end{tabular}

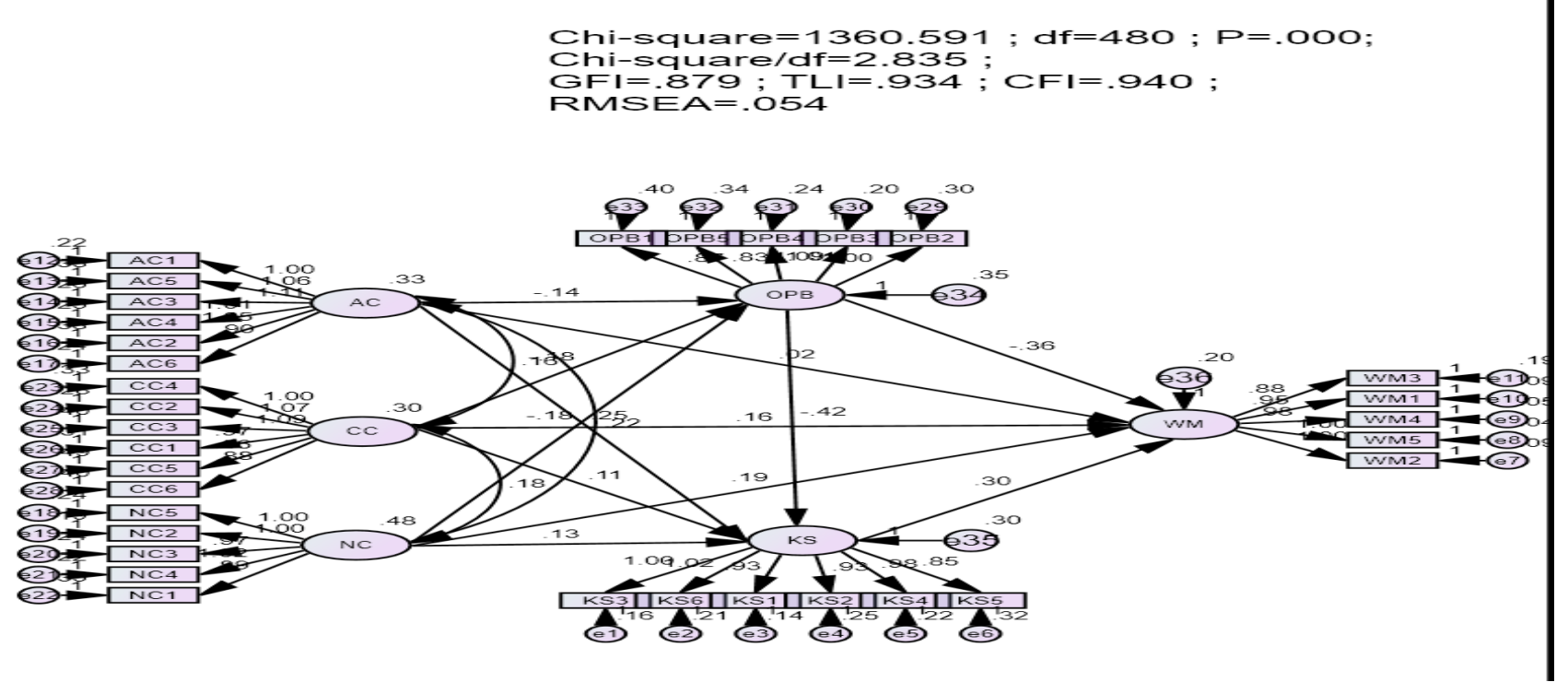

Figure 2: SEM model analysis

Table 3: SEM analysis results for the relationships in the model

\begin{tabular}{|l|c|c|c|c|c|c|}
\hline Hypothesis & Relationship & Mean & SE & CR & $\boldsymbol{P}$ & Conclusion \\
\hline H1 & OPB <--- AC & -0.143 & 0.063 & -2.281 & 0.023 & Accepted \\
\hline H2 & OPB <--- CC & -0.185 & 0.064 & -2.910 & 0.004 & Accepted \\
\hline H3 & OPB <--- NC & -0.184 & 0.050 & -3.636 & 0.000 & Accepted \\
\hline H4 & KS <--- AC & 0.248 & 0.059 & 4.208 & 0.000 & Accepted \\
\hline H5 & KS <--- CC & 0.112 & 0.059 & 1.898 & 0.058 & Rejected \\
\hline H6 & KS <--- NC & 0.127 & 0.047 & 2.711 & 0.007 & Accepted \\
\hline H7 & WM <--- AC & 0.015 & 0.048 & 0.320 & 0.749 & Rejected \\
\hline H8 & WM <--- CC & 0.163 & 0.048 & 3.390 & 0.000 & Accepted \\
\hline H9 & WM <--- NC & 0.194 & 0.039 & 5.048 & 0.000 & Accepted \\
\hline H10 & WM <--- OPB & -0.357 & 0.041 & -8.645 & 0.000 & Accepted \\
\hline H11 & WM <--- KS & 0.299 & 0.038 & 7.798 & 0.000 & Accepted \\
\hline H12 & KS <--- OPB & -0.423 & 0.046 & -9.104 & 0.000 & Accepted \\
\hline
\end{tabular}


Table 4: Results of descriptive statistical analysis of the variables' values

\begin{tabular}{|l|c|c|c|c|c|}
\hline Variables & $\mathbf{N}$ & Min & Max & Mean & $\begin{array}{c}\text { Std } \\
\text { deviation }\end{array}$ \\
\hline AC & 636 & 1.33 & 5.00 & 3.7673 & 0.63052 \\
\hline CC & 636 & 1.17 & 5.00 & 3.7246 & 0.59490 \\
\hline NC & 636 & 1.00 & 5.00 & 3.4969 & 0.71602 \\
\hline OPB & 636 & 1.00 & 5.00 & 2.1626 & 0.66331 \\
\hline KS & 636 & 1.00 & 5.00 & 3.6164 & 0.68995 \\
\hline WM & 636 & 1.00 & 5.00 & 3.8082 & 0.66777 \\
\hline
\end{tabular}

In terms of the relationship between affective commitment and work motivation, this study shows that affective commitment has only an indirect impact on employee motivation, rather than a direct impact on employee motivation through the two mediating factors of opportunistic behavior and knowledge sharing of the employee.

In terms of the relationship between continuance commitment and work motivation, the study shows that continuance commitment has both direct and indirect impacts on employee motivation through the mediating factor of opportunistic behavior of the employee.

In terms of the relationship between normative commitment and work motivation, this study shows that normative commitment has both direct and indirect impacts on employee motivation through both mediating factors of opportunistic behavior and knowledge sharing of the employee.

Moreover, for testing the impact of opportunistic behavior on knowledge sharing of the employee, the hypothesis $\mathrm{H} 12$ is also accepted with a significance level of $\mathrm{P}<0.000<0.05$ and a regression weight of $-0.423(<0)$. Thus, it can be concluded that opportunistic behavior has a negative impact on the knowledge sharing of employees in Vietnamese enterprises (see Table 3).

Theimportanceoforganizationalcommitmenttoemployee motivation in Vietnamese enterprises and the mediating role of opportunistic behavior and knowledge sharing can be obviously seen. Furthermore, the determination of the mean also shows the reality of each factor in this research for employees in Vietnamese enterprises. With the highest mean of the variables in the model at 3.8082, employee motivation is quite high. However, if compared to the general indices of other factors in business and management, this index is still at a relative level.

In addition, the mean of opportunistic behavior is 2.1626 . In comparison with other factors in the model, this factor is evaluated at the lowest level, which reflected the positive aspects in business activities. However, this is still a relatively high value if compared to a factor that reflects the negative aspects in business activities. Enterprises should pay more attention to the opportunistic behaviors of individuals. It is necessary to set specific targets for all employees in each unit and to encourage employees to perform well through policies of fair evaluation and recognition of achievements and reasonable motivation creation. The enterprises should improve internal control in order to limit self-seeking behavior and a dependent mentality at work (see Table 4).

\section{Conclusions and Recommendations}

The study has verified the direct and indirect impacts of organizational commitment on employee motivation through two mediating factors - opportunistic behavior and knowledge sharing - in the context of Vietnamese enterprises. The results show that among the factors of organizational commitment, normative commitment has both direct and indirect impacts on employee motivation through two mediating factors: opportunistic behavior and knowledge sharing. Meanwhile, affective commitment has no direct impact; however, it has indirect impact on employee motivation in enterprises through the two abovementioned mediating factors. Continuance commitment also has a direct impact; however, it only has an indirect impact on employee motivation through opportunistic behavior. In addition, the study shows that opportunistic behavior has a negative impact on the knowledge sharing of employees. Based on the findings, we offer recommendations to improve employee motivation in Vietnamese enterprises as follows:

Firstly, in terms of affective commitment, enterprises should take measures to transparently deliver their development orientation to employees at the appropriate time so that they can clearly understand the development orientation of the enterprise and build their own development orientation.

Secondly, in terms of continuance commitment, it is necessary to create a working environment in which the enterprises recognize and assess employees in a fair and transparent manner. When employees are acknowledged for their contributions and treated in a proper and fair manner, they will be motivated and do not want to leave the organization because they are satisfied with their work and believe that their efforts are worthwhile.

Thirdly, in terms of normative commitment, managers should know how to create inspiration and strong attachment of the employees by commitments to values and benefits for employees when they fulfill their work.

Fourthly, in terms of knowledge sharing, enterprises should create a harmonious and friendly working environment, encouraging knowledge sharing among employees from the work reality, experiences, and knowledge from schools and training courses. 
Fifthly, in terms of opportunistic behavior of employees, enterprises should establish specific targets for each employee in each unit. They should improve internal control to limit self-seeking behaviors and a dependent mentality at work.

\section{References}

Becker, H.S. (1960). Notes on the concept of commitment. American Journal of Sociology, 66(1), 32-40.

Burgess, D. (2005). What motivates employees to transfer knowledge outside their work unit? Journal of Business Communication, 42(4), 324-348.

Chennamaneni, A. (2006). Determinants of knowledge sharing behaviors: Developing and testing an integrated theoretical model. Arlington, TX: Doctoral dissertation, The University of Texas at Arlington.

Doan, T.T.T., Nguyen, L.C.T., \& Nguyen, T.D.N. (2020). Emotional Intelligence and Project Success: The Roles of Transformational Leadership and Organizational Commitment. Journal of Asian Finance, Economics and Business, 7(3), 223-233. https://doi. org/10.13106/jafeb.2020.vol7.no3.223

Hair, J.F., Anderson, R.E., Tatham, R.L., \& Black, W.C. (1998). Multivariate Data Analysis (5th Edition). Upper Saddle River, NJ: Prentice Hall.

Hardiningsih, P., Udin, U., Masdjojo, G.N., \& Srimindarti, C. (2020). Does Competency, Commitment, and Internal Control Influence Accountability?. Journal of Asian Finance, Economics and Business, 7(4), 223 - 233. https://doi. org/10.13106/jafeb.2020.vol7.no4.223

Jadhav, V., Seetharaman, A., \& Rai, S. (2017). Employee Expectation to Demonstrate Innovative Work Behaviour in Asia. Journal of Asian Finance, Economics and Business, 4(1), 67-78. http://dx.doi.org/10.13106/jafeb.2017.vol4.no1.67

Jarnal, M. (1984). Job stress and job performance controversy: an empirical assessment. Organizational Behavior and Human Performance, 33, 1-21.

Katsikeas, C.S., Dionysis, S, \& Daniel, C. (2009). Developing successful trust-based international exchange relationships. Journal of International Business Studies, 40(1), 132-155.

Kinman, G. (2001). Pressure points: A review of research on stressors and strains in UK academics. Journal Educational Psychology, 21, 471-472.

Kothuri, S. (2002). Knowledge in organizations definition, creation, and harvesting. Retrieved from http://www.gse. harvard.edu/ t656_web/Spring_2002_students/kothuri_s mita_knowledge_in_orgs.htm.

Lincoln,J.R, \& Kalleberg,A.L.(1990). Culture, ControlandCommitment: A Study of Work Organization and Work Attitudes in the United States and Japan. Cambridge, MA: Cambridge University Press.

Maponya, P.M. (2004). Knowledge management practices in academic libraries. A case study of the University of Natal, Pietermaritzburg libraries, South Africa.
Mathieu, J.E., \& Zajac, D.M. (1990). A review and meta-analysis of the antecedents, correlates, and consequences of organizational commitment. Psychological Bulletin, 108(2), 171-194.

Meyer, J.P., Allen, N.J. (1991). A three-component conceptualization of organizational commitment. Human Resource Management Review, 1(1), 61-89.

Mobley, W.H., Griffeth, R., Tay, H.H., \& Meglino, B.M. (1979). Review and conceptual analysis of the employee turnover process. Psychological Bulletin, 86(3), 493-522.

Morgan, R.M., \& Hunt, S.D. (1994). The commitment-trust theory of relationship marketing. Journal of Marketing, 58(3), 20-38.

Mowday, R., Steers, R., \& Porter, L. (1979). The measurement of organizational commitment. Journal of Vocational Behavior, 14, 224-247.

Mowday, R.T., Porter, L.W., \& Steers, R.M. (1982). EmployeeOrganization Linkages: The Psychology of Commitment, Absenteeism, and Turnover. New York: Academic Press.

Pierce, J.L., \& Dunham, R.B. (1987). Organizational commitment: pre-employment propensity and initial work experiences. Journal of Management, 13(1), 163-178.

Porter, L.W., Steers, R.M. Mowday, R.T, \& Boulian, P.V. (1974). Organizational commitment, job satisfaction, and turnover among psychiatric technicians. Journalof Applied Psychology, 59, 603-609.

Reichers, A.E. (1985). A review and reconceptualization of organizational commitment. Academy of Management Review, $10,465-476$.

Ritzer, G., \& Trice, H.M. (1969). An empirical study of Howard Beckerside - bet theory. Social Force, 47(6), 475-478.

Salancik, G.R. (1977). Commitment and the control of organizational behavior and belief. In B.M. Staw \& G.R. Salancik (Eds.), New Directions in Organizational Behavior (pp. 1-54), Chicago: St. Clair Press.

Staw, B.M. (1977). Two sides of commitment. Paper presented at the annual meeting of the Academy of Management, Orlando.

Steers, R.M. (1977). Antecedents and outcomes of organizational commitment. Administrative Science Quarterly, 22, 46-56.

Steers, R.M. (1979). The measurement of organizational commitment. Journal of Vocational Behavior, 14(2), 224-247.

Steers, R.M., \& Porter, L.W. (1983). Motivation: New directions for theory and research. Academy of Management Review, 17(1), 80-88.

Stringer, C., \& Didham, J. (2011). Motivation, pay satisfaction, and job satisfaction of front-line employees. Qualitative Research in Accounting \& Management, 8(2), 161-179.

Tett, R.P., \& Meyer, J.P. (1993). Job satisfaction, organizational commitment, turnover intention, and turnover: Path analyses based on meta-analytic findings. Personnel Psychology, 46(2), 259-293.

Tsui, A.S., Zhang, Z.X., Wang, H., \& Xin, R. (2006). Unpacking the relationship between CEO leadership behavior and organizational culture. The Leadership Quarterly, 17, 113-137.

Williamson, O.E. (1975). Markets and Hierarchies: Analysis and Antitrust Implications. New York: Free Press. 